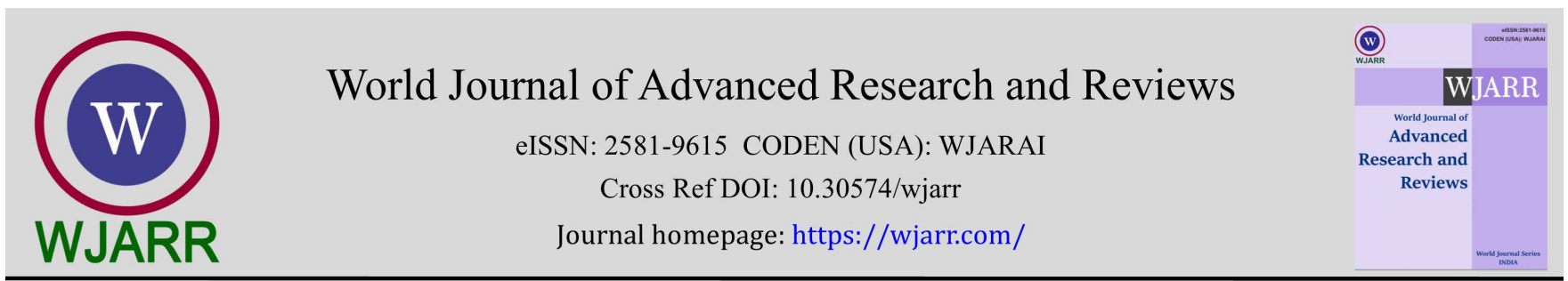

(REVIEW ARTICLE)

\title{
An overview on trematodes developing disease complications causing cancer in human
}

\author{
Mohammad Salim ${ }^{1,}{ }^{*}$, Mohammad Shahid Masroor ${ }^{2}$ and Shagufta Parween ${ }^{3}$ \\ ${ }_{1}^{1}$ Sanjay Gandhi Smriti Govt. Autonomous P.G. College, Sidhi, A.P.S. University, Rewa (M.P.), India. \\ 2 People's College of Dental Sciences \& Research Center, People's University, Bhopal (M.P.), India. \\ 3 Dept. Of Human Anatomy, All India Institute of Medical sciences (AIIMS), Bhopal (M.P.) India.
}

World Journal of Advanced Research and Reviews, 2021, 12(01), 362-374

Publication history: Received on 15 September 2021; revised on 18 October 2021; accepted on 20 October 2021

Article DOI: https://doi.org/10.30574/wjarr.2021.12.1.0535

\begin{abstract}
This is very surprising for us that still most of the peoples are not mentally prepared to accept the fact that some of the human cancers are caused by certain bacteria, viruses, fungi and some of the photosynthetic microorganisms. And, this is found again very shocking if the causal organisms are the worms. A variety of human trematodes developed several fatal diseases like urinary and biliary interruptions, high grade jaundice and even stone formation in human if not treated well within time. Similarly, Schistosoma haematobium causes bladder cancer and Opisthorchis viverrini and Clonorchis sinensis developed cholangiocarcinoma. The present review deals with the study of certain trematodes parasitizing in human developing disease complications causing cancer. And, this is carried out with the help of recent researches done so far in the field of human helminthic oncology and parasitology
\end{abstract}

Keywords: Human helminths; Trematodes; Flatworms; Flukes; Diseases; Cancer in human

\section{Introduction}

Helminths are a group of worms simply categorizing into nematodes, trematodes and cystodes. Trematodes are globally distributed in different parts of the world being easily transmitted via contaminated soil and water and their respective hosts. They are the kind of animals having no spinal cord but the specific oral organs to suck the food. Trematodes are caused by the trematodes like Schistosoma haematobium, a blood fluke causing schistosomiasis (human bladder cancer) ; Clonorchis sinensis, a Chinese liver fluke causing fish borne human cholangiocarcinoma; Opisthorchis viverrini, a southeast Asian liver fluke causing opisthorchiasis or human cholangiocarcinoma; Fasciola hepatica, a sheep and cattle liver fluke causing human fasciliasis; Fasciolopsis buski, an intestinal pig fluke causing human fasciolopsiasis and Paragonimus westermani, an eastern Asian lung fluke causing human paragoniasis [1-12]. The above-mentioned flatworms and flukes are important as they cause various diseases and cancer in human. Therefore, these worms are being discussed in the present review in the light of recent researches done so far in the field of helminthology.

\section{Discussion}

The review discusses the kind of helminths involved in producing cancers in human. Trematodes are found in humans as parasites disseminated in various body parts developing diseases, malignancies and cancer. The following discussion on certain trematodes causing cancer is a part of helminthic parasitology describing their mode of action of developing cancer in human [13-15].

\footnotetext{
${ }^{*}$ Corresponding author: Mohammad Salim

Sanjay Gandhi Smriti Govt. Autonomous P.G. College, Sidhi, A.P.S. University, Rewa (M.P.), India

Copyright (C) 2021 Author(s) retain the copyright of this article. This article is published under the terms of the Creative Commons Attribution Liscense 4.0.
} 


\subsection{Schistosoma haematobium (Schistosomiasis)}

Schistosoma haematobium develops schistosomiasis or bilharzia in human. This is a kind of digenetic trematode, urinary bladder, blood fluke infection of developing countries in Africa, South America the Caribbean, the Middle East and Asia. The disease is more prevalent in Africa and Middle East but occasionally seen in Western Asia. Countrywise this is more common in Egypt, China, Zimbabwe, Iraq and Sudan. Nearly, 2 lac deaths occur every year due to schistosomiasis worldwide. This is spread by the exposure of contaminated water having parasites. The infective cercariae are free swimming [16-24].

In 1851, Theodor Maximillian Bilharz, a German physician and pathologist discovered a parasite while working at Kasr El- Eini hospital in Cairo. Thus bilharzia or bilharziasis is named after Theodar Bilharz. Lateron, in 1915 Lieper, an English scientist discovered the intermediate host as snail, the Bulinus [25-27].

The parasites entered in the human body either by the larvae released by the fresh water snail or the ingestion of eggs contaminated water mixed with the human feces. There are two main types as intestinal and urinogenital schistosomiasis found in humans with five species involved. They are Schistosoma haematobium, S. mansoni, S. japonicum, S. mekongi and S. guineensis. S. haematobium is a human bladder worm [7,22,23,28].

Swimmers itch or popular itchy skin rash appears at the site of initial infection which is lasted in about 4 days. After one to two months the infected individual may present fever, enlarged spleen, liver and lymph nodes. Eosinophilia and some pulmonary symptoms may also occur. Either larvae or eggs entered in the human body develop into the adult schistosomes. It is the only blood fluke that infects the urinary bladder causing bladder cancer in human. The parasite is dioecious and male kept the female in their gynaecophoric canal as their life partner. Females are quite larger than males but slender and smooth fully adjustable in the male canal. The female only leaves the male briefly for laying eggs either in intestine or urinary bladder. An adult female produces 1000 eggs per day through out their life and the average lifespan of a parasite is about 3 to 4 years. These embryonated eggs penetrate the bladder mucosa to form tumor either benign or malignant. [28-31].

Urinary tract infections are a frequent complications of urinary tract dysfunctions caused by the S. haematobium. The infection may lead to extraurinary complications, popularly known as the Bilharzial cor pulmonale. They are frequent urination often associated with hematuria, painful and difficult micturition (dysuria), discomfort in the groin, obstructive uropathy and kidney failure due to bacterial infections. As the disease was very common in Egypt, the ancient Egyptians believed the passing of blood from urine was a good sign of puberty as male menstruation equivalent to menstrual cycle often occurring in females. [36-37].

Schistosoma haematobium has been categorized in Group 1 carcinogenic microorganisms as the agents definitely carcinogenic to humans by the IARC, 2011[38,39]. Around the world about $3 \%$ of all urinary bladder cancers are caused by the $S$. haematobium. It causes inflammation, ulceration, cell proliferations, fibrosis and [40]. As a consequence, most people suffering from chronic schistosomiasis and bladder cancer develop squamous cell carcinoma [41]. This is prevalent in areas of Egypt, Iraq, Zambia, Malawi and Kuwait [42].

During the development of cancer, nitrosamines are produced by $S$. haematobium. It has been proved experimentally that the nitrosamines in association with $S$. haematobium produces neoplastic changes in baboons $[43,44]$. Similarly, some other changes also occur during the course of cancer development in patients suffering from schistosomal infections described as under:

- $\quad$ Reactive oxygen species (ROS) and inflammatory cells like increased levels of eosinophils are found frequently in the patients suffering from schistosomiasis [45,46].

- Mutation in tumor suppressor gene p53 and that production of oncoproteins such as Bcl-2 have been noted in patients suffering from schistosomiasis $[42,46,47]$.

- Schistosomiasis bladder cancer samples have more genes methylated with increased levels of 06methyldeoxyguanosine due to DNA alkylation causing DNA breaks [44,48-50].

Further, the other species of Schistosoma has not been authentically reported as cancer causing microorganisms. However, there are some reports as $S$. mansoni is linked with liver, colorectal and prostate cancer [46]. And, the role of $S$. japonicum in the development of cancer is also not very clear but seems to be associated with both liver and colorectal cancer [19]. 
Diagnosis with the help of microscopic techniques, rapid diagnostic tests for antigen detection, urine reagent strips and PCR assays are conducted. The drug of choice is a quinolone derivative as praziquantel. However, the efficacy of the drug is only 82 to $88 \%$. Human and bovine vaccines to control the schistosomiasis are in various stages of development [35,51-58].

\subsection{Opisthorchis viverrini (Opisthorchiasis and Cholangiocarcinoma)}

Opisthorchis viverrini is a zoonotic fish worm, popularly known as the Asian liver fluke causing opisthorchiasis and cholangiocarcinoma (CCA), a cancer of the bile duct in humans. While the same parasite was discovered by Poirier in 1886 from an Indian fishing cat (Prionailurus viverrus), the first human case was discovered by Lieper in 1995 . The International Agency for Research on cancer has categorized the O. viverrini as a Group 1 biological carcinogen in 2009. This is mostly found in Thailand, Laos, Vietnam and Combodia. Nearly, $10 \%$ of the Thai populations are infected with the cholangiocarcinoma. [1, 10,59-67].

The definitive hosts are humans and other pisciovorous vertebrate animals like dogs, cats, rats and pigs. Similarly, snails of the species Bithnia and the Indian cat fishes are the first and second intermediate hosts of the disease respectively. A human body is a reservoir of the parasite where sexual reproduction occurs. The eggs thus produced and released contaminate the fresh water bodies infecting the fishes and snails. The raw fishes when consumed repeat the cycle again. The raw fish dishes are very common in countries where opisthorchiasis occurs. $[1,68,69]$.

Further, the adult worms found in upper small intestine ultimately reach the biliary tree where they sexually mature developing cancer of the bile duct. Sometimes, these adult worms are also found in gall bladder and pancreatic duct. The infective eggs are discharged through the bile juice in small intestine and finally released via feces in the environment. The average lifespan of an adult worm is 25 years. [68-71].

The initial clinical symptoms of the disease are either asymptomatic or mild as dyspepsia, anorexia, constipation abdominal pain, diarrhoea, edema in legs, ascites and eosinophilia. But in severe infection it may cause enlarged nonfunctional gall bladder, hepatomegaly, cholangitis, cholecystitis and cholangiocarcinoma. Further, as the disease is not a life threatening one initially, chronic infection may only lead to bile duct cancer after 30 to 40 years. Similarly, its ability to cause cancer is further worsened as the infection has been found to be associated with Helicobacter pylori causing simultaneously stomach ulcer and cancer [60,62,63,70-72].

The disease is diagnosed by detecting the eggs in feces using the Kato technique. However, more sensitive tests are also available like ELISA and PCR. Proper cooking of fishes is the only way to prevent the disease properly. Currently, there is no approved drug for the infection, however, the drugs like praziquantel, albendazole, tribendinidine, artimisinin and miltefosine are in practice [73-77].

\subsection{Clonorchis sinensis (Chlonorchiasis)}

Clonorchis sinensis is a Chinese liver fluke, which infects the fish-eating mammals like dogs, cats, rats, pigs, camels, buffaloes including humans. Humans have been found as the definitive host of the parasite. Kobayashi and Masatomo Moto in 1911 and 1918 discovered snail and fishes as their first and second intermediate hosts respectively. The International Agency for Research on Cancer has classified the Clonorchis sinensis as potent biological carcinogen in Group 1 in 2009. It causes bile duct cancer in human and has been found to be the third- most prevalent parasitic worm globally. This is most prevalent in Russia, Japan, China, Taiwan, Korea and Vietnam [78-82].

The parasite was discovered by a British physician Jame McConnell in 1874 while working at Medical College Hospital in Kolkata. He saw the swollen liver with distended and blocked bile ducts by black vermicular bodies in Chinese carpenter during the course of his post martem. He then published his observations in a journal named as "Lancet" in August 1875. In 1907, Arther Looss gave the name Clonorchis sinensis, a genus different from Opisthorchis viverrine [78].

Clonorchiasis is a kind of disease developed in human caused by the Clonorchis sinensis. The parasite while feeding on bile infects the common bile duct and gall bladder developing biliary inflammation, bile duct obstruction, periductal fibrosis, cholangiocarcinoma, liver abscess and hepatic carcinoma. The clinical symptoms of the disease are indigestion, intermittent obstruction of the bile ducts, cholangitis, gall bladder stone, abdominal discomfort, nausea, vomiting, diarrhoea, anorexia, weight loss and jaundice. $[9,80,82,83]$.

This is a flattened, dorsiventral, leaf shaped liver fluke measuring about 15 to $20 \mathrm{~mm}$ in length. It has got oral sucker at the anterior end acting as mouth. As this is a hermaphroditic animal it contains both male and female reproductive organs. A single rounded ovary with two highly branched testes are found at the posterior end. A common genital pore 
well connected with the uterus from the ovary and seminal ducts from the testes is found. The eggs are quite similar to Opisthorchis viverrini and 0 . felineus are difficult to distinguish [84-85].

The eggs are released via the biliary tract and excreted out along with the human feces. The miracidial larva developed inside the fertilized egg is usually visible. Upon development these larvae are sedimented in water and simply being eaten by the snails. After ingestion by snails, the miracidial larvae hatched from the eggs, reach the digestive gland via penetrating the intestinal wall where carcarian larvae are formed by metamorphosis. These larvae now leaves the body of snail to find out the secondary intermediate host as fish. However, since this is a non-feeding stage, if they do not find fish die within 2 to 3 days $[1,84,86]$.

Further, within an hour of larval penetration in fishes, the cysts are formed and the larvae became metacercariae. Humans are infected when undercooked or raw fishes are eaten. These cysts are digested in stomach with the help of gastric juices. The free larvae reached the bile duct through intestinal mucosa after penetration. They keep on feeding bile to mature within a month. Also, they start laying eggs to repeat the cycle again. An adult fluke feeding on bile can live in the ducts on an average 30 years without any clear symptoms appeared $[82,85,86]$.

The diagnosis is done by detecting the eggs in feces and duodenal aspirate by formaline- ether concentration technique (FECT) and Kato- Katz method. However, the serological test like ELISA is also available to distinguish the eggs from Opisthorchis viverrini and O. felineus. Similarly, to detect the biliary cirrhosis CT scan, ultrasound or MRI are also conducted. The drugs used to treat the infection are albendazole, praziquantel, triclabendazole, bithionol and levamisole [82,87-90].

\subsection{Paragonimus wastermani (Paragonimiasis)}

Paragonimus wastermani is also called as the Japanese lung fluke or oriental lung fluke that infects humans developing paragonimiasis. This is prevalent in Far East Asian countries like China, Taiwan, Japan, Philippines, India, Mangolia, North and South Korea and South America. P. wastermani is named after Pieter Wasterman, a zookeeper who noted the fluke in a Bengal tiger. It was discovered by Coenraad kerbert in 1879. Similarly, the first human infection was recognized from Taiwan in 1879. This is a crabfish borne disease developing lung inflammations in human. The domestic cat is a good reservoir of a variety of lung flatworms transmitting in humans [91-96].

P. wastermani is an hermaphroditic animal. Like other trematodes it has also got oral and ventral suckers. Adult flukes are reddish- brown in colour measuring about 7 to $16 \mathrm{~mm}$ and ovoid in shape. Unembryonated eggs are released in the sputum or feces of human, felines and cats, pigs or dogs. Miracidia developed inside the eggs hatched after two weeks. They then penetrate the snails to form many daughter redie which shed crawling cercariae into fresh water. These crawling cercariae penetrate the crabs encysting in muscles becoming metacercaria. Humans and felines eating the crabfishes are infected by the metacercaria released from cysts. They penetrate the intestinal wall to reach the lungs where they mature into an adult worm [97-99].

Paragonimiasis can cause illness like pneumonia or stomach flu. The usual clinical symptoms of the pulmonary paragonimiasis are intermittent cough, expectoration of discolored reddish- brown mucus on cough, fever, bronchitis, hemoptysis, dyspnea on exertion, skin rashes and urticaria, abdominal pain, diarrhoea and the chest radiographic abnormalities. The incubation period of the disease is nearly 3 months and the disease may persist in humans for over 20 years. $[93,98,100]$.

The worm stimulates an inflammatory response in lungs allowing it to form capsule. These capsules ulcerate and heal over time mimicking as tuberculosis. Then most common cause of hemoptysis worldwide has always been either tuberculosis or paragonimiasis. Sometimes, pleural paragonimiasis may also occur where there is frequently no cough and the ova are not split out in the sputum developing pleural effusion misdiagnosed as isolated tuberculosis. In addition, very rarely, extra pulmonary paragonimiasis is seen in which these worms are disseminated either in the spinal cord or heart developing paralysis and death respectively. In addition, it can also affect the liver, spleen, breast, abdomen, skin and brain. [8,93,98,101,102,103].

The detection of eggs in stool, sputum, CSF or in lung effusion fluid may demonstrate the presence of the disease. ZiehlNeelson staining and needle aspiration cytology are useful tools for the same purposes [104-107]. However, the detection of antibodies in blood are helpful in confirming the disease. Various techniques like ELISA, PCR and immunoblot can also be helpful to differentiate the paragonimiasis from [108-110]. 
Paragonimiasis is rare in the United States but common in Asia. Humans are more commonly infected by eating raw undercooked salted or pickled freshwater crabs or crayfishes containing cysts. Proper cooking of crabs or crayfishes before eating can only control and prevent the infection properly. Praziquantel is a drug of choice for physicians. Bithinol is also used with some side effects as skin rashes and urticaria. Some other specific medications with the high cure rates using under strict medical supervision are also available as niclofan and triclabendazole [10,111-113].

\subsection{Fasciola hepatica (Fascioliasis)}

Fasciola hepatica is a common liver fluke or sheep liver fluke. Although, the human fascioliasis is distributed worldwide, this is infrequently found in India making it an incidental host. This is one of the largest leaf shaped liver flukes parasitizing in liver and bile duct and can be visualized with the naked eyes. Fascioliasis is caused by the two species of digenetic trematodes named as Fasciola hepatica and Fasciola gigantica. Both of them cause similar diseases in human. $F$. hepatica lives in the liver of definitive hosts like sheep, goat, cows, buffaloes and human, their intermediate host is air breathing snail. They are hermaphrodites having both male and female reproductive organs reproducing either sexually or asexually. Similarly, they have got small but a powerful oral sucker. [114-116]

The entered eggs in snail developed in cercaries which are encysted to become metacercariae and released to adhere on aquatic vegetation. Herbivorous animals are infected by eating the contaminated vegetation. Similarly, the humans are also infected either by the consumption of contaminated freshwater plants especially the watercress or by the consumption of undercooked or raw liver. After ingestion, these metacercariae encysts in the duodenum and migrated into the biliary ducts through the intestinal wall, the peritoneal cavity and the liver parenchyma. In human, the time taken a fluke to mature in an adult is about 3 to 4 months. An adult fluke produces 25000 eggs per day. These eggs are passed out through feces contaminating the water and infecting the snails to repeat the cycle again. [117,118]

The usual clinical symptoms of the disease are nausea, vomiting, intermittent fever with extreme abdominal pain in epigastrium or right hypochondrium. Since, the humans adapted as a definitive hosts some ectopic infections like "Halzoun" may occur. This is a kind of buccopharyngeal infection where the Fasciola worms are attached in the buccopharyngeal mucosa by their suckers causing edema of the soft palate, pharynx and larynx. Some other ectopic infections may also occur as in lungs and subcutaneous tissues in the form of skin rashes and urticaria. Severe infections can develop dysphagia, pharyngitis, hepatitis, cholangitis, pancreatitis and the feeling of airways obstruction possibly due to the foreign bodies in the throat. [116,119]

Chronic phase occurs when the worms mature in the bile duct causing rupture of the liver capsule into the peritoneal cavity developing peritonitis (Almendras et al. 1997) [120]. While fibrosis and the chronic inflammations are usually concerned with the development of cancer, this is still found unclear whether Fasciola is associated with the increased risk of cancer. There are evidences of an association between Fasciola infection with liver fibrosis and cirrhosis but very little is known about causing cancer. [121-122]

Further, stool microscopy is not very useful as the eggs can be detected only after 2 months of infection. However, ELISA and western blot tests are specific. X rays may show the liver abscess. Ultrasound may also show the adult worm's inhabitating in specific organs. Similarly, cholangiography may reveal mulberry like multiple cystic dilatations of the ducts. Suergeries are sometimes helpful. Triclabendzole is the drug of choice and found to be very effective. Praziquantel is not effective. Bithionol is moderately effective but has more side effects. Similarly, nitazoxanide is effective but not recently recommended by the physicians due to certain reasons. [114,123-128]

\subsection{Fasciolopsis buski (Fasciolopsiasis)}

Fasciolopsis is an intestinal giant fluke of about $7.5 \mathrm{~cm}$ long with the only one species recognized as Fasciolopsis buski parasitizing in human. This is a very common and the largest known fluke parasite of human. The other known mammalian host is pig. In London, George Busk isolated the pathogen in 1843 from duodenum of a sailor. Fasciolopsis buski, the only species was named after the discoverer. The entire life cycle was studied and published by Barlow Claude Herman in 1925. The disease is endemic in China, Taiwan, Indonesia, Japan and Malaysia. The disease is also found in Thailand and Bangladesh. This is now known to be a common intestinal parasite of humans and pigs in India especially in Bihar and Uttar Pradesh [115,129-133].

F. buski is a hermaphroditic animal producing more than 25000 eggs per day. These unembryonated eggs are discharged in the intestine and released via feces. The infective miracidia are developed in eggs in about 7 to 9 weeks to infect snails. Ultimately, after several developmental stages as sporocysts and rediae, the cercarie are released from snails to encyst as metacercarie on aquatic vegetations like lotus, water chestnut, water spinach, water caltrop and bamboo. Humans and pigs are infected when these vegetations are ingested by them. They excyst in the duodenum to attach in 
the intestinal wall. They are developed in adults in about 3 months. The average life span of an adult worm is about a year. [115, 132, 134-137].

Further, light infections are usually asymptomatic. However, severe infections may cause diarrhoea, abdominal pain, biliary and intestinal obstruction with perforatios, ascites and appendicitis. The allergic reactions caused by the absorption of allergic metabolites released by the pathogen developed lethal consequences in an individual. The diagnosis is based on the detection of eggs in feces or vomitus. Surgical intervention for Fasciolopsis buski infection is also performed. Praziquantel is a drug of choice. However, other drugs like tetrachloroethylene, thiabendazole, mebendazole, levamisole, pyrantel pamoate, oxyclozanide, hexachlorophene and nitroxynil are also effective.[11,131,138-151]

\section{Conclusion}

Trematodiases are caused by the trematodes, popularly known as the flatworm or fluke infections. They are usually transmitted either by the contaminated food or infected aquatic organisms. The majority of trematodiases are reported from east and Southeast Asian countries. These infections, if not treated well within time they may cause certain lethal complications in human like schistosomal obstructive uropathy and kidney failure caused by the Schistosoma haemtobium. Similar is the case with Opisthorchis viverrini and Clonorchis sinensis causing cholangitis, cholecystitis, hepatomegaly, liver abscess and gall bladder stone formation in human. Trematodes are multicellular organisms that can live in or outside of the body. The flatworms and flukes are rather more dangerous than roundworms and tapeworms as they cause cancer in human. A carcinogenic role is recognized to the Schistosoma haematobium leading to urinary badder cancer and to Clonorchis sinensis and Opisthorochis viverrini causing cholangiocarcinoma in human. IARC, 2011 have already categorized several trematodes that are able to cause cancer in humans as 1st category- Group 1, biological agents definitely carcinogenic to humans viz. Schistosoma haematobium, Clonorchis sinensis and Opisthorchis viverrini, 2nd category Group 2 biological agents probably carcinogenic to humans viz. Schistosoma japonicum and 3rd category Group 3 biological agents not classified as to its carcinogenic to humans viz. Schistosoma mansoni and Opisthorchis felineus. Opisthorchis viverrini and Clonorchis sinensis are liver-flukes that have been linked to increased risk of developing cancer of the bile ducts. The bile ducts are tubes that connect the liver for the intestines. These infections come from eating raw or uncooked freshwater fishes. They occur in East Asia and are rare in other parts of the world. As these liver flukes have been reported to cause cancer in human as cholangiocarcinoma (CCA) are certified by the IARC, 2011 as Group 1 carcinogen. They are found in the biliary system developing hepatobiliary diseases causing heptomegaly, inflammations, mechanical obstruction, Jaundice, cholangitis, cholecystitis, cholelithiasis, adenomatous hyperplasia and periductal fibrosis. The exact mechanism of cancer development is not very clear. N- nitroso- compounds produced during the course of cancer development may lead to DNA damage. Similarly, $O$. viverrini and $C$. sinensis secreted some mitogenic proteins and other substances causing cell proliferations. Some other trematodes developing complications are paragonimus wastermani, Fasciola hepatica and Fasciolopsis buski. Further, paragonimiasis is quite difficult to diagnose mimicking as tuberculosis. Sometimes, other extra pulmonary paragonimiasis also occurs in breast, spinal cord and brain developing malignancies, paralysis and death respectively. Similarly, Fasciola hepatica chronic infection may cause rupture of the liver capsule into the peritoneal cavity developing peritonitis. Lastly, the severe allergic reactions may also occur due to the release of toxic substances by the Fasciolopsis buski. This is a notable parasite, mostly found in southern and eastern Asia. It causes a disease known as fasciolopsiasis in human and pigs. F. Buskii is usually an ectoparasite residing in the human small intestine causing little harm as colitis, Crohn's disease or irritable bowel syndrome. Most of the times, they are expelled out from the bowel, but when transmitted in other parts of the body like liver, kidney or uterus, they certainly cause cancer. If possible, they are being killed with isopropyl alcohol, benzene or with the help of some medicinal herbs. It also causes AIDS in the body. Lastly, the physician's choice of drugs for the treatment of flatworms and flukes are praziquantel, albendazole and triclabendazole. However, some other drugs like tribendinidine, artimisinin, miltefosine, bithionol, livamisole and niclofan have also been used in some specific.

\section{Compliance with ethical standards}

\section{Financial support and sponsorship}

No financial support was granted during the course of this research work.

\section{Disclosure of conflict of interest}

The authors have declared no conflict of interest. 


\section{Statement of informed consent}

Informed consents were obtained from all participants.

\section{References}

[1] Chai JY, Darwin MK, Lymbery AJ. Fish- borne parasitic zoonoses: status and issues. Int. J. for Parasitology. 2005; 35(11-12): 1233-54.

[2] Keiser J, Utzinger. Foodborne trematodes. Clin. Microbiol. Rev. 2009; 22(3): 466-483.

[3] Keiser and Utzinger J. The drugs we have and the drugs we need against helminth infections.Advances in Parasitology. 2010; 73: 197-230.

[4] Harhay MO, Horton J, Olliaro PL. Epidemiology and control of human gastrointestinal parasites in children. Expert Review of Anti- infective Therpay. 2010; 8(2): 219-234.

[5] Ziegelbauer K, Speich B, Mausezahl D, Bos R, Keiser J, Utzinger J. Effect of sanitation on soil transmitted helminth infection: systematic review and metaanalysis. PLoS Medicine. 2012; 9(1): e1001162.

[6] Carpio A, Fleury A, Romo ML, Abraham R. Neurocysticercosis: the good, the bad and the missing. Expert Rev Neurother. 2018; 8(4): 289-301.

[7] Colley DG, Bustinduy Al, Sector WE, King CH. Human schistosomiasis. The Lancet. 2014; 383 (9936): $2253-2264$.

[8] Kohli S, Farooq O, Jani RB, Wolfe GI. Cerebral paragonimiasis: an unusual manifestation of a rare parasitic infection. Pediatr. Nuerol. 2015; 52: 366.

[9] Kim TS, Pak JH, Kim JB, Bahk YY. Clonorchis sinensis, an oriental liver fluke, as a human biological agent of cholangiocarcinoma: a brief review. BMB Reports. 2016; 49(11): 590-597.

[10] Hughes T, O'Connor T, Techsen A, Taylor RSD. Opisthorchiasis and cholangiocarcinoma in Southeast Asia: an unresolved problem. Int. J. Gen. Med. 2017; 10: 227-237.

[11] Jha AK, Jha SK. Fasciolopsis buski endoscopic diagnosis of: revisited (with video). JGH Open. 2020; 4: 284-286.

[12] Lalrinkima H, Lalchandama C, Jacob SS, Raina OK, Lallianchhunga MC. Fasciolosis in India. An overview. Exp Parasitol. 2021; 222: 108066.

[13] Machicado C, Marcos LA. Carcinogenesis associated with parasites other than Schistosoma, Opisthorchis and Clonorchis: A systematic Review. Int. J. Cancer. 2016; 138 (12): 2915-2921.

[14] Lalchhandama K. The making of oncology: The tales of false carcinogenic worms. Science Vision. 2017; 17(1): 3352.

[15] Monica CB, Joachim R. Editorial: Parasites and cancer. Frontiers in Medicine. 2019; 6.

[16] Mills EA, Machattie C, Chadwick CR. Schistosoma haematobium and its life cycle in Iraq. Transactions of the Royal Society of Tropical Medicine and Hygiene. 1936; 30(3): 317-322.

[17] Chitsulo L, Englels D, Montresor A, Savioli L. The global status of schistosomiasis and its control. Acta Tropica. 2000; 77(1): 41-45.

[18] Ross AG, Sleigh AC, Li Y, Davis GM, Williams GM, Jiang Z. Schistosomiasis in the People's Republic of China: Prospects and challenges for the $21^{\text {st }}$ century. Clin. Microbiol. Rev. 2001; 14 (2): 270-295.

[19] Khurana S, Dubey ML, Mella N. Association of parasitic infections and cancers. Ind J Med Microbiol. 2005; 23(2): 74-79.

[20] Barkat R. Epidemiology of schistosomiasis in Egypt: Travel through time: Review Journal of Advanced Research. 2013; 4(5): 425-432.

[21] Mutapi F. Getting a GRiPP on everyday schistomiasis: experience from Zimbabwe. Parasitology. 2016; 12: 16241632.

[22] Vos T, Allen C, Arora M, Barber RM, Bhutta ZA, Brown A. Global regional and national life expectancy, all-cause mortality for 249 causes of death, 1980-2015: a systematic analysis for the global burden of disease study. Lancet. 2016; 388(10053): 1459-1544. 
[23] Antoni S, Ferlay J, Jamal A, Bray F. Bladder cancer incidence and mortality: A global overview and recent trends. European Urology. 2017; 71(1): 96-108.

[24] Kabuyaya M, Chimbari MJ, Manyangadze T, Samson M. Efficacy of Schistosoma haematobium and re- infection rates among school- going children in the Ndumo area of uMkhanyakude district, KwaZulu- Natal, South Africa. Infectious Diseases of Poverty. 2017; 6(1): 83.

[25] Leiper RT. Report on the results of the Bilharzia mission in Egypt. Journal of the Royal Army Medical Corps. 1915; 25(2): 1-55.

[26] Rollinson D, Stothard JR, Southgate VR. Interactions between intermediate snail hosts of the genus Balinus and Schistosomes of the Schistosoma haematobium group. Parasitology. 2001; 123: 245-260.

[27] Tan SY, Ahana A. Theodor Bilharz (1825-1862): discoverer of schistosomiasis. Singapore Med. J. 2007; 48(3): 184-185.

[28] Bottieau E, Clerinx J, Colebunders R, Van EM. Imported Katayama fever: clinical and biological features at presentation and during treatment. The Journal of Infection. 2006; 52(5): 339- 345.

[29] Berry A, Iriart X, Fillaux J, Magnaval JF. Urinary schistomiasis and cancer. Bulletin de la Societe de Pathologie Exotique. 2017; 110(1): 68-75.

[30] Elbaz T, Esmat G. Hepatic and intestinal schistosomiasis, review. Journal of Advanced Research. 2013; 4(5): 445452.

[31] Akl MM. Bilharziasis: A granulomatous parasitic disorder with grave implications. In: Mansourian BP, Wojtczak A, Sayers BM (eds). Medical Sciences, Oxford (UK): Eolss Publishers Co Ltd. 2009; 1: 374-400.

[32] Hutchinson HS. The pathology of bilharziasis. The American Journal of Pathology. 1928; 4(1): 1-16.

[33] Ibrahim H. Bilharziasis and bilharzial cancer of the bladder. Annals of the Royal College of Surgeons of England. 1948; 2 (3): 129-141.

[34] Rutherford P. The diagnosis of schistomiasis in modern and ancient tissues by means of immunocytochemistry. Chungara, Revista de Antropologia Chilena. 2000; 32(1).

[35] Khalaf I. Shokeir A, Shalaby M. Urologic complications of genitourinary schistosomiasis. World Journal of Urology. 2011; 30(1): 31-38.

[36] Feldmeler H, Krantz I, Poggensee G. Female genital schistosomiasis: a neglected risk factor for the transmission of HIV? Transactions of the Royal society of Tropical Medicine and Hygiene. 1995; 89 (2): 237.

[37] Yegorov S, Joag V, Galiwango RM, Good SV, Okech B, Kaul R. Impact of endemic infections on HIV susceptibility in Sub- Saharan Africa. Tropical Diseases, Travel Medicine and vaccines. 2019; 5: 22.

[38] Bouvard V, Baan R, Straif K, Grosse Y, Guha N. A review of human carcinogenesis - Part B: biological agents. The Lancet. 2009; 10(4): 321-322.

[39] Creusy C, Certad G, Guyot K, Dei-Cas E. Parasites and oncogenesis with a special reference to gastro-intestinal neoplasia induced by Cryptosporidium parvum, In : Detection of bacteria, viruses and fungi. Viola-Magni M. (ed.), NATO Series Science for Peace, Springer, Berlin. 2010; 381-388.

[40] Catherine DM, Silvia F. Infections and cancer: established associations and new hypotheses. Critical Reviews in Oncology/ Hematology. 2008; 70(3): 183-194.

[41] Cohen SM and Johansson SL. Epidemiology and etiology of bladder cancer. Urol. Clin. N. Am. 1992; 19: $421-428$.

[42] Mostafa MH, Sheweita SA, O' Conner PJ. Relationship between schistosomiasis and bladder cancer. Clin. Microbiol. Rev. 1999; 12: 97-111.

[43] Hicks RM, James C, Webbe G. Effect of Schistosoma haematobium and N-butyl-N-(4-hydoxybutyl) nitrosamine on the development of urothelial neoplasia in the baboon. Br. J. Cancer. 1980; 42: 730-755.

[44] IARC. Monograph on the evaluation of carcinogenic risks to humans. W.H.O. Part B. Biological Agents, Lyon, France. 100: 1-487, 2011.

[45] Salim E, Morimura K, wanibuchi H. Elevated oxidative stress and DNA damage and repair levels in urinary bladder carcinoma associated with schistosomiasis. Int. J. Cancer. 2008; 123: 601-608.

[46] Vennervald BJ, Polman K. Helminths and malignancy. Parasite Immunol. 2009; 31: 686-696. 
[47] Chaudhary KS, Lu QL, Lalani EN. Expression of bcl-2 and p53 oncoproteins in schistosomiasis-associated transitional and squamous cell carcinoma of urinary bladder. Br. J. Urol. 1997; 245: 78-84.

[48] Badawi AF, Mostafa MH. And Cooper DP. Promutagenic methylation damage in bladder DNA from patients with bladder cancer associated with schistosomiasis and from normal individuals. Carcinogenesis. 1992; 13: 877-881.

[49] Badawi AF, Copper DP and O' Connor PJ. O6-alkyl-guanine DNA alkyltransferase activity in schistosomiasisassociated human bladder cancer. Eur. J. Cancer. 1994; 30A: 1314-1319.

[50] Gutierrez MI, Siraj AK, Bhatia K. CpG island methylation Schistosoma and non-Schistosoma-associated bladder cancer. Mod. Pathol. 2004; 17: 1268-1274.

[51] Pearce EJ, MacDonald AS. The immunobiology of schistosomiasis. Nature Reviews Immunology. 2002; 2(7): 499511.

[52] Tchuente LA, Shaw DJ, Polla L, Ciolo D, Vercruysse J. Efficacy of praziquantel against Schistosoma haematobium infection in children. Am. J. Trop. Med. Hyg. 2004; 6: 778-782.

[53] Angelucci F, Basso A, Bellelli A, Brunori M, Pica ML, Valle C. The anti- schistosomal drug praziquantel is an adenosine antagonist. Parasitology. 2007; 134(9): 1215-1221.

[54] Gray DJ, Ross AG, Li YS, McManus DP. Diagnosis and management of schistosomiasis. BMJ. 2011; $342: 2651$.

[55] Ochodo EA, Gopalkrishna G, Spek B, Polman K. Circulating antigen tests and urine reagent strips for diagnosis of active schistosomiasis in endemic areas. The Cochrane Database of Systematic Reviews. 2015; 3: CD009579.

[56] Utzinger J, Becker SL, Van LL, Knopp S. New diagnostic tools in schistosomiasis. Clinical Microbiology and Infection. 2015; 21(6): 529-542.

[57] Mutro NM, Salieb BGB, Battegay M, Hunziker P. Schistosomiasis from established diagnostic assays to emerging micro/ nanotechnology based rapid field testing for clinical treatment and epidemiology. Precision Nanomedicine. 2019; 3: 439-458.

[58] Riveau G, Schacht AM, Dompnier JP, Sec M. Safety and efficacy of the rSh28GST urinary schistosomiasis vaccine: A phase 3 randomized, controlled trial in Senegalese children. PLoS Neglected Tropical Diseases. 2018; 12(12): e0006968.

[59] Andrews RH, Sithithaworn P, Petney TN. Opisthorchis viverrini: an underestimated parasite in world health. Trends in Parasitology. 2008; 24(11): 497-501.

[60] Kaewpitoon N, Kaewpitoon SJ Pengsea P, Sripa B. Opisthorchis viverrini: the carcinogenic human liver fluke. World Journal of Gastroenterology. 2008; 14(5): 666-674.

[61] Sripa B. Concerted action is needed to tackle liver fluke infections in Asia. PLoS Neglected Tropical Diseases. 2008; 2(5): e232.

[62] Young ND, Campbell BE, Hall RS, Jex AR, Gasser RB. Unlocking the transcriptomes of two carcinogenic parasites, Clonorchis sinensis and Opisthorchis viverrini. PLoS Neglected Tropical Diseases. 2010; 4(6): e719.

[63] Sripa B, Brindley PJ, Mulvenna J, Laha T, Smout MJ, Loukas A. The tumorigenic liver fluke Opisthorchis viverrinimultiple pathways to cancer. Trends in Parasitology. 2012; 28 (10): 395-407.

[64] Eom KS, Yong TS, Sohn WM, Chai JY, Min DY. Phommasack B. Prevalence of helminthic infections among inhabitants of Lao PDR. The Korean Journal of Parasitology. 2014; 52 (1): 51-56.

[65] Miyamoto K, Kirinoki M, Matsuda H, Hayashi N, Kitikoon V. Field survey focused on Opisthorchis viverrini infection in five provinces of Cambodia. Parasitology International. 2014; 63 (2): 366-373.

[66] Kaewpitoon N, Kootanavanichpong N, Kompor P, Loyd RA. Review and current status of Opisthorchis viverrini infection at the community level in Thailand. Asia Pacific Journal of Cancer Prevention. 2015; 16 (16): 6825-6830.

[67] Dao TT, Bul TV, Abatih EN, Gabriel S, Dorny P. Opisthorchis viverrini infections and associated risk factors in a low land area of Binh province, Central Vietnam. Acta Tropica. 2016; 157: 151-157.

[68] Wykoff DE, Harinasuta C, Winn MM. Opisthorchis viverrini in Thailand - The life cycle and comparison with 0. felineus. The Journal of Parasitology. 1965; 51(2): 207-214.

[69] Rachprakhon P, Purivirojkul W. Very low Prevalence of Opisthorchis viverrini s.I. cercariae in Bithynia simensis snails from the canal network system in the Bangkok Metropolitan region, Thailand. Parasite. 2021; 28: 2. 
[70] Stripa B, Kaewkes S, Sithithavorn P, Mairiang E, Laha T, Smout M, Brindley PJ. Liver fluke induces cholangiocarcinoma. PLoS Medicine. 2007; 4 (7): e201.

[71] Smout MJ, Laha T, Mulvenna J, Sripa B, Jones A, Loukas A. A granulin like growth factor secreted by the carcinogenic liver fluke, Opisthorchis viverrini promotes proliferation of host cells. PLoS Pathogens. 2009; 5(10): e1000611.

[72] Sripa B. Pathology of opisthorchiasis: an update. Acta Tropica. 2003; 88(3): 209-220.

[73] Jongsuksuntigul P, Imsomboon T. Opisthorchiasis control in Thailand. Acta Tropica. 2003; 88(3): $229-232$.

[74] Keiser J, Utzinger JR. Artemisinin and synthetic trioxolanes in the treatment of helminth infections. Current Opinion in Infectious Diseases. 2007; 20(6): 605-612.

[75] Soukhathammavong P, Odermatt p, Sayasone S, Keiser J. Efficacy and Safety of mafloquine, artesunate, mafloquine- artesunate, tribendimidine and praziquantel in patients with Opisthorchis viverrini: A randomized, exploratory, open label phase 2 trial. The Lancet Infectious Diseases. 2011; 11(2): 110-118.

[76] Saengsawang P, Promthet S, Bradshaw P. Infection with Opisthorchis viverrini and use of praziquantel among a working- age population in northeast Thailand. Asian Pacific Journal of Cancer Prevention. 2013; 14(5): 29632966.

[77] Pechdee P, Chaiyasaeng M, Sereewong C, Chaiyos J, suwannatrai A, Tesana S. Effects of albendazole, artesunate, praziquantel and miltefosine on Opisthorchis viverrini cercariae and mature metacercariae. Asian Pacific Journal of Tropical Medicine. 2017; 10(2): 126-133.

[78] Yoshikava K. Clonorchis and Chlonorchiasis. In: Dawes, Ben (ed). Advances in Parasitology 1967; 4, Burlington: Elsevier. 53-101.

[79] Sohn WM. Fish- borne zoonotic trematodes metacerariae in the Republic of Korea. The Korean Journal of Parasitology. 2009; 47: 103-113.

[80] Hong ST, Fang Y. Clonorchis sinensis and clonorchiasis an update. Parasitology International. 2012; 61(1): 17-24.

[81] Yoshida Y. Clonorchiasis- A historical review of contributions of Japanese parasitologists. Parasitology International. 2012; 61 (1): 5-9.

[82] Tang Ze-Li, Yan H, Xin - Bing Yu. Current status and perspectives of Clonorchis sinensis and clonorchiasis, omics, prevention and control. Infect Dis Poverty. 2016; 5(1): 71.

[83] Huang Y, Chen W, Wang X, Liu H, Ralph SA. The carcinogenic liver fluke Clonorchis sinensis: New assembly, reannotation and analysis of the genome and characterization of tissue transcriptomes. PLoS ONE. 2013; 8(1): e54732.

[84] Kim JH, Choi MH, Bae YM, Oh JK, Ito A. Correlation between discharged worms and fecal egg counts in human chlonorchiasis. PLoS Neglected Tropical Diseases. 2011; 5(10): e1339.

[85] Qian Mb, Utzinger J, Keiser J, Zhou XN. Chlonorchiasis. The Lancet. 2016; 387(10020): 800-810.

[86] Hung N, Dung Do, Lan A, Van HH, Canh L. Current status of fish- borne zoonotic trematode infections in Gia Vien district, Ninh Binh province, Vietnam. Parasites and Vectors. 2015; 8(1): 21.

[87] Park MS, Yu JS, Kim KW, Kim MJ, Chung JP, Yoo HS. Recurrent pyogenic cholangitis comparison between MR cholangiography and direct cholangiography. Radiology. 2001; 220(3): 677-682.

[88] Jang YJ, Byun JH, Yoon SE, Yu E. Hepatic parasitic abscess caused by clonorchiasis. Korean Journal of Radiology. 2007; 8(1): 70-73.

[89] Xu LL, Xue J, Zhang YN, Qiang HQ, Xiao SH. In vitro effect of seven anthelmintic agents against adult Clonorchis sinensis. Zhongguo Ji Sheng Chong Xue Yu Ji Sheng Chong Bing Za Zhiu. 2011; 29(1): 10-15.

[90] Wu W, Qian X, Huang Y, Hong Q. A review of the control of Clonorchiasis sinensis and Taenia solium teaniasis/ cysticercosis in China. Parasitology Research. 2012; 111(5): 1879-1884.

[91] Kerbert C. Zur Treamatoden- kenntniss. Zoologischer Anzeiger. 1878; 1: 271-273.

[92] Chung HL, Ho LY, Hsu CP, Tsao WJ. Recent progress in studies of Paragonimus and paragonimiasis control in China. China Med. J. 1981; 94: 483-494. 
[93] Minh VD, Engle P, Greenwood JR, Clair R. Pleural paragonimiasis in a Southeast Asian refugee. Am. Rev, Respir Dis. $1981 ; 124: 186-188$.

[94] Johnson JR, Falk A, Iber C, Davies S. Paragonimiasis in the United States: a report of nine cases in Hmong immigrants. Chest. 1982; 82: 168-171.

[95] Johnson RJ, Johnson JR. Paragonimiasis in Indochinese refugees: roentgenographi findings and clinical correlationjs. Am. Rev. Respir Dis. 1983; 128: 534-538.

[96] Procop GW. North American paragonimiasis (caused by Paragonimus kellicotti) in the context of global paragonimiasis. Clinical Microbiology Reviews. 2009; 22 (3): 415-446.

[97] Yokogawa M. Paragonimus and paragonimiasis. Adv. Parasitol. 1965; 3: 99-158.

[98] Miyazaki I, Habe S. A newly recognized mode of human infection with the lung fluke, Paragonimus westermani: J parastitol. 1976; 62: 646-648.

[99] Imelda V, Luz E, Velasquez, Ivan DV. Morphological description and life cycle of Paragonimus sp. (Treamatoda: Troglotrematidae): causal agent of human paragonimiasis in Colombia. Journal of Parasitology. 2003; 89(4): 749755.

[100] Nawa Y. Re- emergence of paragonimiasis. Internal Medicine. 2000; 39(5): 353-354.

[101] Heath HW, Marshall SG. Pleural paragonimiasis in a Laotin child. Pediatric Infectious Diseases Journal. $1997 ; 16$ (12): 1182-1185.

[102] Jun SY, Jang J, Ahn SH. Paragonimiasis of the breast: Report of a case diagnosed by fine needle aspiration. Acta Cytol. 2003; 47: 685.

[103] Xia Y, Ju Y, Chen J, You C. Hemorrhagic stroke and cerebral paragonimiasis. Stroke. 2014; $45: 3420$.

[104] Romeo DP, Pollock JJ. Pulmonary paragonimiasis: diagnostic value of pleural fluid analysis. South Med. J. 1986; 79: 241-243.

[105] Slemenda SB, Maddison SE, Jong EC, Moore DD. Diagnosis of paragonimiasis by immunoblot. Am. J. Trop. Med. Hyg. 1988; 39: 469.

[106] Rangdaeng S, Alpert LC, Khiyami A. Pulmonary paragonimiasis. Report of a case with diagnosis by fine needle aspiration cytology. Acta Cytol. 1992; 36: 31.

[107] Slesak G, Inthalad S, Basy P. Ziehl- Neelsen staining technique can diagnose paragonimiasis. PLoS Negl Trop Dis. 2011; 5: 1048.

[108] Imai J. Evaluation of ELISA for the diagnosis of Paragonimiasis westermani. Trans R Soc Trop Med Hyg. 1987; 81: 3.

[109] Waikagul J. Serodiagnosis of paragonimiasis by enzyme linked immunosorbent assay and immunoelectrophoresis. Southeast Asian J Trop Med Public Health. 1989; 20: 243.

[110] Sugiyama H, Morishima Y, Kameoka Y, Kawanaka M. Polymerase chain reaction (PCR) - based molecular discrimination between Paragonimus westermani and P. miyazaki at the metacercarial stage. Mol. Cell Probes. 2002; 16: 231.

[111] Johnson RJ, Long EC, Dunning SB. Paragonimiasis: diagnosis and the use of praziquantel in treatment. Rev. Infect. Dis. 1985; 7: 200.

[112] Pachuki CT, Levendowski RA, Brown VA, Vruno MJ. American paragonimiasis treated with praziquantel. N. Eng J Med. 1984; 311: 582-583.

[113] Keiser J, Engles D, Buscher G, Utzinger J. Triclabendazole for the treatment of fascioliasis and paragonimiasis. Expert Opin. Investig. Drugs. 2005; 14: 1513.

[114] Esteban JG, Bargues MD, Mas- Coma S. Geographical distribution, diagnosis and treatment of human fascioliasis: a review. Res. Rev. Parasitol. 1998; 58: 13-42.

[115] Mas CS, Bargues MD, Valero MA. Fascioliasis and other plant- borne treamatode zoonoses. Int. J. Parasitol. 2005; 35: 1255-1278.

[116] Tolan RW. Fascioliasis due to Fasciola hepatica and F. gigantica infection: An update on this neglected tropical disease. Laboratory Medicine. 2011; 42 (2): 107-116. 
[117] Andrews JS. Life cycle of Fasciola hepatica In: Dalton, JP (ed). Fasciolosis. Wallingford Oxon, UK: CABI pub. 1999; 1-30.

[118] Hurtrez BS, Meunier C, Durand P, Renaud F. Dynamics of host- parasite interactions: the example of population biology of the liver fluke (Fasciola hepatica). Microbes and Infection. 2001; 3 (10): 841-849.

[119] Behm CA, Sangster NC. Pathology, pathophysiology and clinical aspects. In: Dalton JP (ed.), Fasciolosis. CAB International Publishing Wallingford. 1999; 185-224.

[120] Almendras JM, Rivera MJ, Seijas MJ, Almendras JK. Hepatic fascioliasis in children: uncommon clinical manifestations. Arq Gastroenterol. 1997; 34 (4): 241-247.

[121] Marcos LA,Terashima J. Fascioliasis mimicking malignancy in humans. Peruv. J. Parasitol. 2013 ; 21 (1): $55-63$.

[122] Machicado C, Jorge DM, Maco V, Angelica T, Luis AM. Association of Fasciola hepatica infection with liver fibrosis, cirrhosis and cancer: A systematic review. PLoS Negl. Trop. Dis. 2016; 10 (9): e0004962.

[123] Zimmerman GL, Jen LW, Cerro JE, Farnsworth KL, Wescott RB. Diagnosis of Fasciola hepatica infections in sheep by an enzyme- linked immunosorbent assay. Am. J. Vet. Res. 1982; 43 (12): 2097-2100.

[124] Taira N, Yoshifuji H, Boray JC. Zoonotic potential of infection with Fasciola spp. by consumption of freshly prepared raw liver containing immature flukes. Int. J. Parasitol. 1997; 27 (7): 775-779.

[125] Rossignol JF, Abaza H, Friedman H. successful treatment of human fascioliasis with nitazoxanide. Trans. R. Soc. Trop. Med. Hyg. 1998; 92 (1): 103-104.

[126] Hillyer GY. Immunodiagnosis of human and animal fasciolosis. In: Dalton JP, (ed.). Fasciolosis. Wallingford, Oxon, UK: CABI Pub. 1999: 435-447.

[127] Savioli L, Chitsulo L, Montresor A. New opportunities for the control of fascioliasis. Bull. World Health Organ. 1999; 77 (4): 300.

[128] Halferty L, Brennan GP, Hann REB, Edgar HW, Fairweather I. Tegumental surface changes in Juvenile Fasciola hepatica in response to treatment in vivo with triclabendazole. Veterinary Parasitology. 2008; 155 (1-2): 49-58.

[129] Jarroonvesama N, Charoenlarp K, Areekul S, Aswapokee N, Leelarasmee A. Prevalence of Fasciolopsis buski and other parasitic infections in residents of three villages in Sena district, Ayudhaya province. J. Med. Assoc. Thai. 1980; 63: 493-499.

[130] Gilman RH, Mondal G, Maskud M, Alam K, Khan MU. Endemic focus of Fasciolopsis buski in Bangladesh. Am J. Trop Med Hyg. 1982; 31: 796-802.

[131] Weng YL, Zhuang ZL, Jiang HP, Lin GR, Lin JJ. Studies on ecology of Fasciolopsis buski and control strategy of fasciolopsiasis. Zhongguo Ji Sheng Chong Xue Yu Ji Sheng Chong Bing Za Zhi. 1989; 7 (2): 108-111.

[132] Gupta A, Xess A, Dayal VM, Prasad KM, shahi SK. Fasciolopsis buski (giant intestinal fluke) - a case report. Ind. J. Pathol. Microbiol. 1999; 42: 359- 360.

[133] Khurana S. Fasciolopsiasis: endemic focus of a neglected parasitic disease in Bihar. Ind J. Med Microbiol. 2016; 34: 247.

[134] Barlow CH. Experimental ingestion of the ova of Fasciolopsis buski; Also the ingestion of adult Fasciolopsis buski for the purpose of artificial infestation. The Journal of Parasitology. 1921; 8 (1): 40-44.

[135] Barlow CH. The life cycle of the human intestinal fluke Fasciolopsis buski (Lankester). Am. J. Hygiene $1925 ; 98$.

[136] Nakagawa K. The development of Fasciolopsis buski Lankester. Parasitology. 1922; 8(4): 161-166.

[137] Mohanty I, Narasimham MV, Sahu S, Panda P, Parida B. Live Fasciolopsis buski vomited out by a boy. Ann Trop Med Public Health. 2012; 5: 403-405.

[138] Idris M, Rahman KM, Muttalib MA, Azad Khan AK. The treatment of fasciolopsiasis with niclosamide and dichlorophen. J Trop Med Hyg. 1980; 83: 71-74.

[139] Probert Aj, Sharma RK, Singh K, Saxena R. The effect of five fasciolicides on malate dehydogenase activity and mortality of Fasciola gigantica, F. buski and Paramphistomum explanatum. J. Helminthol. 1981; 55 (2): $115-122$.

[140] Bunnag D, Radomyos P, Harinasuta T. Field trial on the treatment of fasciolopsiasis with praziquantel. Southeast Asian J Trop Med Public Health 1983; 14: 216-219. 
[141] Rabbani GH, Gilman RH, Kabir I, Mondel G. The treatment of Fasciolopsis buski in children: a comparison of thiabendazole, mebendaole, levamisole, pyrantel pamoate, hexylresorcinol and tetrachloroethylene. Trans. R. Soc. Trop. Med. Hyg. 1985; 79 (4): 513-515.

[142] Chen XL, Yuan Y, Chen Q, Zhou YS, Zhang XH, Liu H. Studies on detecting antibodies in human sera of Fasciolopsis buski by ELISA. Cent. Chin Norm Univ. 2004; 38: 85-87.

[143] Wang KX, Wang HY, He J, Ye S. Fasciolopsiasis presenting as intestinal obstruction; a case report. Chin J Surg. 2005; 43: 1168.

[144] Sen SM, Yachha SK, Srivastava A, Poddar U. Endoscopic extraction of Fasciolopsis buski. Endoscopy. 2007; 39: e129.

[145] Bhattacharjee HK, Yadav D, Bagga D. Fasciolopsiasis presenting as intestinal perforation: a case report. Trop. Gastroenterol. 2009; 30: 40-41.

[146] Mahajan RK, Duggal S, Biswas NK, Duggal N, Hans C. A finding of live Fasciolopsis buski in an ilestomy opening. J Infect Dev Ctries. 2010; 4: 401-403.

[147] Lee TH, Huang CT, Chung CS. Education and imaging. Gastrointestinal: Fasciolopsis buski infestation diagnosed by upper gastrointestinal endoscopy. J. Gastroenterol Hepatol. 2011; 26: 1464.

[148] Singh UC, Kumar A, Srivastava A, Patel B, Shukla VK, Gupta SK. Small bowel striucture and perforation: an unusual presentation of Fasciolopsis buski. Trop Gastroenterol. 2011; 32: 320-322.

[149] Qureshi AH, Masoodi I, Safiyani AM, Musharaf AH, Shaqhan M. Biliary fascioliasis- an uncommon cause of recurrent biliary colics: report of a case and brief review. Ger Med Sci. 2012; 10: Doc10.

[150] Cao YH, Ma YM, Qiu F, Zhang XQ. Rare cause of appendicitis: mechanical destruction due to Fasciolopsis buski infestation. World J Gastroenterol. 2015; 21: 3146-3149.

[151] Wu X, Wang W, Li Q, Qiang X, Yue L, Li S. Case report: surgical intervention for Fasciolopsis buski infection: a literature review. Am. J. Trop. Med. Hyg. 2020; 103 (6): 2282-2287. 